\title{
English Foxhound
}

National Cancer Institute

\section{Source}

National Cancer Institute. English Foxhound. NCI Thesaurus. Code C53923.

The English Foxhound is a clean-cut, athletic hound, with a long muzzle and wide skull. The ears lay flat to the head. The short, hard coat is usually tri-color (black, white and tan), or bi-color with a white backg round. Height: 21-25 inches (53-63 cm.) Weight: 65-70 pounds (60-63 kg.) 